\title{
Evaluation of functions after surgical treatment in patients with arterial thoracic outlet syndrome using QuickDASH
}

\author{
Arteriyel torasik çıkıs sendromlu hastalarda cerrahi tedavi sonrası \\ fonksiyonların QuickDASH ile değerlendirilmesi
}

Selçuk Köse $\mathbb{D}^{-}$, Servet Özdemir [

Department of Thoracic Surgery, Health Sciences University, Bakırköy Dr. Sadi Konuk Training and Research Hospital, Istanbul, Turkey

\begin{abstract}
Background: The aim of this study was to examine the validity and reliability of the Quick Disability of the Arm, Shoulder and Hand questionnaire in patients with arterial thoracic outlet syndrome.

Methods: A total of 106 patients (15 males, 91 females; mean age: $30.7 \pm 10.2$ years; range, 13 to 60 years) with arterial thoracic outlet syndrome were included in this prospective study between January 2015 and December 2018. The questionnaire was administered to all patients before and six months after surgery. The patients were operated using a transaxillary or supraclavicular approach under general anesthesia.

Results: The Cronbach's alpha value of the questionnaire was found to be 0.85 and the scale consisted of two factors. The change in both the functional status subscale scores $(\mathrm{p}<0.001)$ and the physical pain subscale scores $(\mathrm{p}<0.001)$ were statistically significantly different before and after surgery. At the end of six months, $53 \%$ of the patients with at least one mild difficulty continued to have complaints related to hand, arm and shoulder.

Conclusion: Based on our study results, this questionnaire is a valid and reliable tool for measuring and monitoring disease symptoms in patients with arterial thoracic outlet syndrome.
\end{abstract}

Keywords: Arterial, thoracic outlet syndrome, QuickDASH questionnaire, reliability, validity.

Arterial thoracic outlet syndrome (TOS) occurs as a result of chronic compression of the subclavian artery in the thoracic outlet region. ${ }^{[1,2]}$ It is classified into three groups as arterial TOS, venous TOS, and neurogenic TOS and each three types have different symptoms and physical findings that can be easily

\section{$\ddot{O} Z$}

Amaç: Bu çalışmada, arteriyel torasik çıkış sendromlu hastalarda Hızlı Kol, Omuz ve El Sorunları Anketi’nin geçerliği ve güvenirliği incelendi.

Çalışma planı: Bu prospektif çalışmaya, Ocak 2015-Aralık 2018 tarihleri arasında arteriyel torasik çıkış sendromlu 106 hasta (15 erkek, 91 kadın; ort. yaş: $30.7 \pm 10.2$ yıl; dağılım, 13-60 y1l) alındı. Ameliyattan önce ve altı ay sonra tüm hastalara anket uygulandı. Hastalar genel anestezi altında transaksiller veya supraklaviküler yaklaşım ile ameliyat edildi.

Bulgular: Anketin Cronbach alfa değeri 0.85 olarak bulundu ve ölçek iki faktörden oluşuyordu. Fonksiyonel durum alt ölçek puanlarında $(\mathrm{p}<0.001)$ ve fiziksel ağrı alt ölçek puanlarındaki $(\mathrm{p}<0.001)$ değişim, ameliyat öncesi ve ameliyat sonrasında istatistiksel olarak anlamlı düzeyde farklı idi. Altıncı ayın sonunda, en az bir hafif güçlüğü olan hastaların \%53'ünde, el, kol ve omuz ile ilgili şikayetler devam ediyordu.

Sonuç: Çalışma sonuçlarımıza göre, bu anket arteriyel torasik çıkış sendromu hastalarda hastalık semptomlarını ölçmek ve izlemek için geçerli ve güvenilir bir araçtır.

Anahtar sözcükler: Arteriyel, torasik çıkış sendromu, QuickDASH anketi, güvenirlik, geçerlik.

identified ${ }^{[1]}$ Neurogenic TOS is the most common type, accounting for more than $90 \%$ of all TOS cases, while the other TOS types are rarer. ${ }^{[3]}$ Some authors have shown that arterial origin types of the TOS may be more common and arterial-neurogenic TOS may also coexist. ${ }^{[4]}$

Received: April 07, 2020 Accepted: June 14, 2020 Published online: January 13, 2021

Correspondence: Servet Özdemir, MD. SBÜ, Bakırköy Dr. Sadi Konuk Eğitim ve Araştırma Hastanesi, Göğüs Cerrahisi Kliniği, 34180 Bakırköy, İstanbul, Türkiye. Tel: +90 505 - 3572434 e-mail: servetozdemir74@hotmail.com 
Different results have been obtained related to the course of the ongoing symptoms in patients with TOS after surgery. Surgical intervention provides a significant improvement in quality of life in TOS patients and arterial TOS patients show physical and mental improvement in a shorter period compared to neurogenic TOS patients. ${ }^{[5]}$ In a meta-analysis including 12 studies, $90 \%$ of the arterial and venous TOS groups achieved an excellent/good improvement. ${ }^{[6]}$ In 23 TOS patients evaluated before and after surgery with the Disabilities of the Arm, Shoulder and Hand (DASH) questionnaire, the treatment response varied depending on the types of disease; i.e., venous TOS and neurogenic TOS. ${ }^{[7]}$ In a retrospective study, 62 cases of TOS in 56 patients were evaluated ${ }^{[8]}$ Of these, 36 were neurogenic TOS, 13 were arterial TOS, seven were venous TOS, and six were combined TOS cases. A total of 54\% patients achieved complete recovery and 90\% showed a significant improvement, although functional disorders persisted in TOS patients. In addition, some of the symptoms of the disease may continue long-term after surgery in patients with TOS.

The QuickDASH is a short form of the DASH questionnaire and is a measurement tool used in clinical studies involving disorders of the upper extremity musculoskeletal system. ${ }^{[9,10]}$ In addition, it is one of the measurement tools used in the assessment of the symptoms of patients with TOS and their post-treatment recovery level..$^{[7,8]}$ In this study, we aimed to investigate whether the QuickDASH was a valid and reliable measurement tool in arterial TOS patients who underwent surgery, to identify the factor structure of the QuickDASH in TOS patients, and to evaluate the changes in disease symptoms in TOS patients after surgery.

\section{PATIENTS AND METHODS}

In this prospective, observational study, a total of 111 patients with a preliminary diagnosis of arterial TOS referred from the Physical Therapy and Rehabilitation, Cardiovascular Surgery, Neurosurgery, and Neurology departments to our Thoracic Surgery outpatient clinic between January 2015 and December 2018 were screened. All of the cases evaluated in the study were patients with arterial TOS. The diagnosis of TOS patients who were referred to a thoracic surgery specialist was confirmed based on full medical history, physical examination, plain radiographs, Doppler ultrasound, magnetic resonance imaging (MRI), and computed tomography (CT) (presence of arterial stenosis) findings. The measured arterial flow rate in neutral position with Doppler ultrasound decreased, when it was measured after provocation maneuver. Provocation maneuvers (Adson's, hyperabduction, costoclavicular, and Wright test) were examined by physical examination. The presence of cervical ribs and prolonged $\mathrm{C} 7$ vertebra transverse processes were searched on direct radiographs. The upper extremity arterial and venous blood flow velocities were measured comparatively in neutral by provocation positions on Doppler ultrasound. An intravenous contrast material was administered by MRI, CT and/or angiography to determine arterial compression or thrombosis along the cervicoaxillary canal. The MRI and CT angiography were used to differentiate arterial and neurogenic TOS. Patients who were suspected to have mixed-type TOS as clinical and medical history assessment were evaluated with electromyography to the upper extremity. Cases compatible with neurogenic TOS of the electromyography findings and evaluated as the mixed type were excluded from the study. In addition, neurogenic TOS cases were excluded from the beginning of the study. Patients who refused to undergo surgery, whose signs and symptoms improved with physical therapy, and those with neurogenic TOS and superior sulcus tumors were also excluded. A written informed consent was obtained from each patient. The study protocol was approved by the Bakırköy Dr. Sadi Konuk Training and Research Hospital Ethics Committee. The study was conducted in accordance with the principles of the Declaration of Helsinki.

All patients were operated under general anesthesia. Of all patients, 109 patients were operated using a transaxillary approach, while two were operated with a supraclavicular approach. In two patients with cervical ribs, since the cervical rib was not totally removed with a transaxillary approach, the remaining residual rib part was removed with a supraclavicular approach in a separate session. The scalene muscle divisions, excision of fibrous bands, total rib resection of the first rib and cervical rib, if any, were performed as a procedure of the operation. A special attention was paid to disarticulate the rib resections, particularly from the costovertebral joint.

Five patients were excluded, as they were unwilling to complete the QuickDASH. Therefore, the data of a total of 106 patients (15 males, 91 females; mean age: $30.7 \pm 10.2$ years; range, 13 to 60 years) were included in the study. Demographic and clinical characteristics of the patients were recorded preoperatively. The diagnosis in patients with a vascular pathology was made using CT angiography and magnetic resonance angiography. The subclavian artery and vein compression, intravascular thrombus and stenosis 
were detected (thrombus, $\mathrm{n}=5$; compression, $\mathrm{n}=1$; stenosis, $n=3$ ). The patients with a vascular pathology first applied to the cardiovascular surgery clinic with their current complaints. Medical treatments including thrombolytics, antiaggregants, and anticoagulants were prescribed to the patients in this department. These cases were, then, referred to the thoracic surgery clinic, since there was no clinical improvement despite the medical treatment. Complications were observed in five patients in the postoperative period. Three patients underwent tube thoracostomy due to pneumothorax, one patient had hematoma evacuation, and atelectasis occurred in another patient.

\section{Assessment tool}

The QuickDASH is a short form of the DASH questionnaire and is a measurement tool consisting of 11 questions and is used to measure the symptoms of upper extremity musculoskeletal disorders. ${ }^{[9]}$ The items in the scale assess severity of the disease, and the extent to which the problems of the arm, shoulder and hand affect the quality of life and physical skills. Higher scores indicate a greater level of symptom severity. Each item in the scale is scored between 1 and 5 points, and the total score of the scale is calculated as follows: QuickDASH Score $=[$ (Total score of marked items)/(Number of marked items)-1] $\times 25$. This questionnaire was administered to 106 arterial TOS patients preoperatively and at six months postoperatively.

\section{Statistical analysis}

Statistical analysis was performed using the IBM SPSS version 22.0 software (IBM Corp., Armonk, NY, USA). Descriptive data were expressed in mean \pm standard deviation (SD), median (min-max) or number and frequency. The suitability of the data was evaluated using the Bartlett's sphericity test, Kaiser Meyer-Olkin measure of sampling adequacy (KMO), and correlation matrix results. Factor analysis was used to assess the validity of the QuickDASH. Internal consistency reliability was measured using the Cronbach's alpha. The paired samples t-test was used to measure the change in the mean QuickDASH scores. QuickDASH questionnaire response rates between the preoperative and postoperative periods were compared using Pearson Chi-Square Analysis and Fisher Exact Tests. The relationship between the factors of the scales and the repeated measures was measured using the Pearson correlation analysis. An independent t-test was used to compare the mean scores between the two groups. Normal distribution assumptions were met for all analyses. A $p$ value $<0.05$ was considered statistically significant.

\section{RESULTS}

Of the patients, $18(17.0 \%)$ were bilateral TOS cases (two separate sessions) and $16(15.1 \%)$ were cervical rib cases, while 36 (34\%) underwent intraoperative tube thoracostomy.

The correlation matrices of QuickDASH items were found to be higher than 0.30. The anti-image correlation coefficients were between 0.69 and 0.88 . The variance values of the items were between 0.40 and 0.71 . The factor weight values of the substances were between 0.61 and 0.74 . The KMO value of the scale was calculated as $0.83(\mathrm{p}<0.001)$. According to the factor analysis, the scale consisted of two factors; the factor load of the first factor (Factor 1) was 41.21 and the factor load value increased to 53.03 with the addition of the second factor (Factor 2) (Table 1). The first factor was named as functional state, as the items included in the study measured the individual's functionality and quality of life, while the second factor was named as the state of the degree of physical pain due to the inclusion of the two items which measured the severity of pain in patients (Table 1).

The mean preoperative QuickDASH total score was $67.8 \pm 16.2$, and the mean postoperative six-month QuickDASH total score was $31.7 \pm 19.3$. In the comparison of pre- and postoperative scores, the mean QuickDASH score significantly differed $(\mathrm{t}=18.40, \mathrm{p}<0.001)$. The mean score of preoperative Factor 1 was $32.7 \pm 6.3$, and the mean postoperative Factor 1 score was $20.3 \pm 7.1$. There was a significant difference between the mean pre- and postoperative Factor 1 scores $(\mathrm{t}=16.62, \mathrm{p}<0.001)$. In addition, the mean Factor 2 scores in the preoperative and postoperative period were significantly different $(\mathrm{t}=13.60, \mathrm{p}<0.001)$ (Table 2).

The rates of the participants in TOS who showed no signs of disease (no difficulty) and showed signs of disease (mild difficulty-not at all) according to the scale items were compared. In the preoperative period, the rate of the patients who showed signs of disease on the QuickDASH questionnaire was statistically significant $(\mathrm{p}<0.01)$, except for item $\mathrm{Q} 2$, compared to the rate of the patients in the postoperative period. According to the Q1-Q11 item scores, TOS patients showed at least one symptom in the preoperative period, ranging between 92.2 and 100\%. According to the Q1-Q11 item scores, TOS patients showed at least one symptom (53.8 to $88.7 \%$ ) in the postoperative period (Table 3). 
Table 1. QuickDASH questionnaire validity and reliability analysis results

\begin{tabular}{ccccc}
\hline & Communalities & Factor loading & Item-total correlation & Cronbach's $\alpha$ if item deleted \\
\hline Factor 1 & & & & \\
Q1 & 0.41 & 0.61 & 0.49 & 0.84 \\
Q2 & 0.55 & 0.74 & 0.65 & 0.83 \\
Q3 & 0.53 & 0.70 & 0.60 & 0.83 \\
Q4 & 0.40 & 0.63 & 0.53 & 0.83 \\
Q5 & 0.69 & 0.66 & 0.56 & 0.83 \\
Q6 & 0.41 & 0.64 & 0.55 & 0.83 \\
Q7 & 0.44 & 0.66 & 0.57 & 0.83 \\
Q8 & 0.45 & 0.64 & 0.54 & 0.83 \\
Q11 & 0.51 & 0.70 & 0.62 & 0.83 \\
Factor 2 & & & & 0.85 \\
Q9 & 0.71 & 0.71 & 0.38 & 0.84 \\
Q10 & 0.67 & 0.62 & 0.42 & \\
\hline
\end{tabular}

QuickDASH: Quick Disabilities of the Arm, Shoulder and Hand; Kaiser-Meyer-Olkin Measure of Sampling Adequacy (KMO)= 0.839. Bartlett's Test of Sphericity, Approx. Chi square $=388.484, \mathrm{p}<0.001$. Cumulative variance factor $1=41.216$, Total Cumulative variance $=53,036$, correlation matrix $>0.30$, anti-image correlation $=0.69-0.88$. Cronbach's alpha $=0.85$. Factor $1=$ Functional status, Factor 2= Physical pain.

Table 2. Comparison of pre- and postoperative QuickDASH questionnaire scores

\begin{tabular}{lccccc}
\hline & Mean $\pm \mathrm{SD}$ & $\mathrm{t}$ & $p$ & $95 \% \mathrm{CI}$ & \\
\hline QuickDASH total-preoperative & $67.8 \pm 16.2$ & 18.40 & $<0.001$ & 32.15 & 39.91 \\
QuickDASH total-postoperative & $31.7 \pm 19.3$ & & & & \\
Factor 1- preoperative & $32.7 \pm 6.3$ & 16.62 & $<0.001$ & 10.91 & 13.87 \\
Factor 1- postoperative & $20.3 \pm 7.1$ & & & & \\
Factor 2- preoperative & $8.6 \pm 1.5$ & 13.60 & $<0.001$ & 2.81 & 3.77 \\
Factor 2- postoperative & $5.3 \pm 2.2$ & & & & \\
\hline
\end{tabular}

QuickDASH: Quick Disabilities of the Arm, Shoulder and Hand; SD: Standard deviation; CI: Confidence interval.

According to sex of the patients, the mean preoperative QuickDASH total score $(Z=-1.80$, $\mathrm{p}=0.071)$ and postoperative QuickDASH total score $(\mathrm{Z}=-0.95, \mathrm{p}=0.338)$ were not significantly different between male and female TOS patients.

According to the Pearson correlation analysis, age of the TOS patients and preoperative total score of the QuickDASH $(r=0.26, p<0.01)$, postoperative total score of the QuickDASH $(r=0.26, p<0.01)$, preoperative Factor 1 values $(\mathrm{r}=0.29, \mathrm{p}<0.01)$, Factor 1 postoperative values $(r=0.23, p<0.05)$, Factor 2 postoperative values $(r=0.32, p<0.01)$ were found to be significantly correlated. In addition, the preoperative QuickDASH total scores were found to be significantly associated with the preoperative Factor 1 scores $(\mathrm{r}=0.95, \mathrm{p}<0.01)$ and preoperative Factor 2 scores $(\mathrm{r}=0.56, \mathrm{p}<0.01)$. The postoperative QuickDASH total scores were also significantly correlated with the postoperative Factor 1 scores $(\mathrm{r}=0.94, \mathrm{p}<0.01)$ and postoperative Factor 2 scores $(\mathrm{r}=0.78, \mathrm{p}<0.01)$. There was a significant, positive correlation between the preoperative QuickDASH total scores and postoperative QuickDASH total scores $(r=0.36, p<0.01)$ (Table 4).

A total of 52 of TOS diseases were right-sided and 54 of them were left-sided. In the comparison 
Table 3. Patients with and without symptoms according to QuickDASH questionnaire

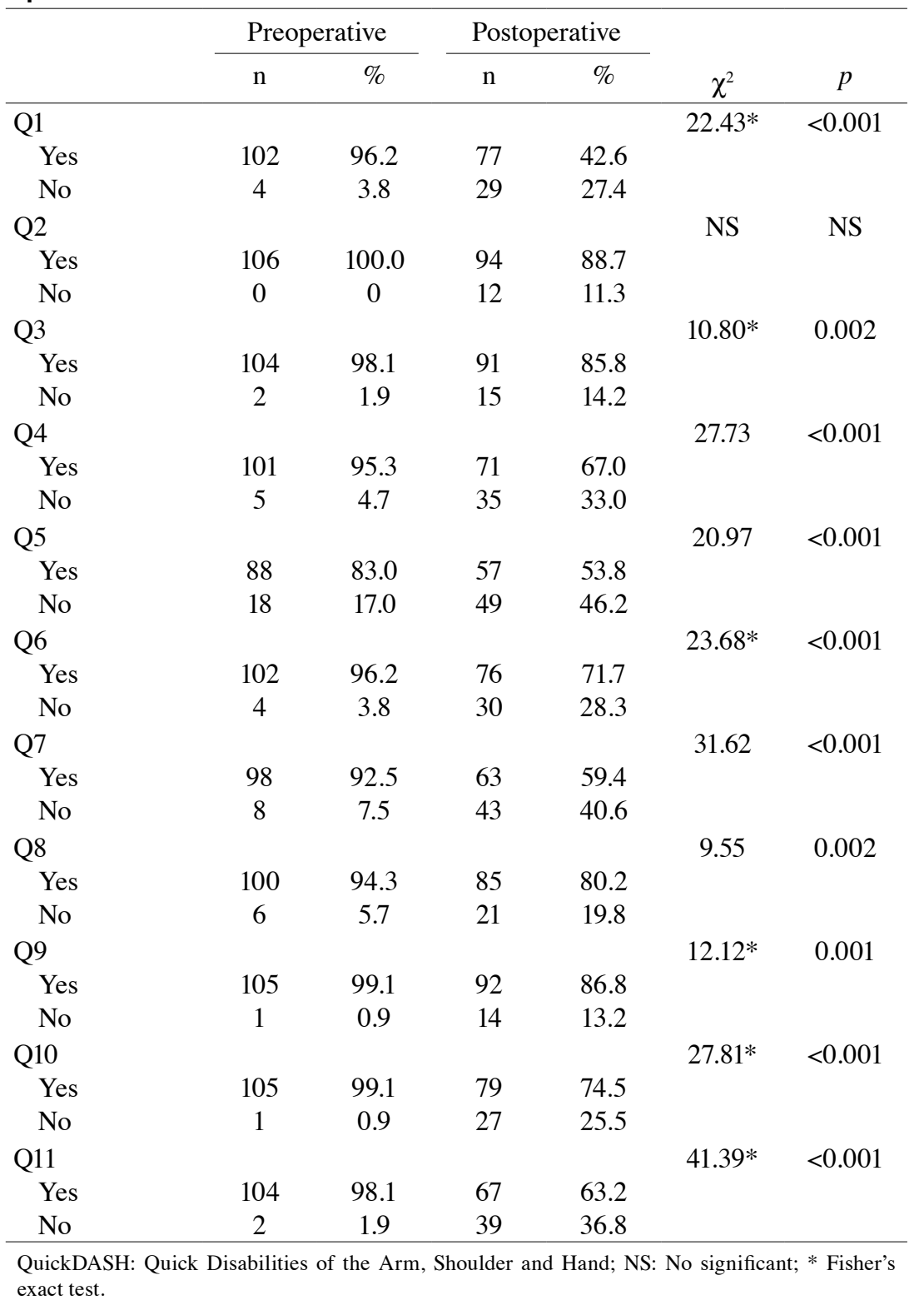

Table 4. Correlation analysis between QuickDASH questionnaire scores and age

\begin{tabular}{lcccccc}
\hline & 1 & 2 & 3 & 4 & 5 & 6 \\
\hline 1- Age & - & & & & & \\
2- Quick DASH total-preoperative & $0.26^{* *}$ & & & & & \\
3- Quick DASH total-postoperative & $0.26^{* *}$ & $0.36^{* *}$ & & & & \\
4- Factor 1- preoperative & $0.29^{* *}$ & $0.95^{* *}$ & $0.34^{* *}$ & & & \\
5- Factor 1- postoperative & $0.23^{*}$ & $0.37^{* *}$ & $0.94^{* *}$ & $0.34^{* *}$ & & \\
6- Factor 2- preoperative & -0.04 & $0.56^{* *}$ & $0.26^{* *}$ & $0.41^{* *}$ & $0.27^{* *}$ & \\
7- Factor 2- postoperative & $0.32^{* *}$ & 0.17 & $0.78^{* *}$ & 0.16 & $0.69^{* *}$ & 0.12 \\
\hline
\end{tabular}

QuickDASH: Quick Disabilities of the Arm, Shoulder and Hand; * <0.05; ** <0.01. 
Table 5. Comparison of QuickDASH questionnaire scores according to the side of TOS

\begin{tabular}{|c|c|c|c|}
\hline & Mean \pm SD & $\mathrm{t}$ & $p$ \\
\hline Quick DASH total scores-preoperative & & 1.42 & 0.159 \\
\hline Right & $70.0 \pm 14.4$ & & \\
\hline Left & $65.6 \pm 17.6$ & & \\
\hline Quick DASH total scores-postoperative & & 1.61 & 0.109 \\
\hline Right & $34.8 \pm 20.5$ & & \\
\hline Left & $28.8 \pm 17.9$ & & \\
\hline Factor 1- preoperative & & 1.29 & 0.197 \\
\hline Right & $33.5 \pm 5.5$ & & \\
\hline Left & $32.0 \pm 6.9$ & & \\
\hline Factor 2- preoperative & & -0.68 & 0.493 \\
\hline Right & $8.5 \pm 1.7$ & & \\
\hline Left & $8.7 \pm 1.4$ & & \\
\hline Factor 1- postoperative & & 2.17 & 0.032 \\
\hline Right & $21.8 \pm 7.6$ & & \\
\hline Left & $18.9 \pm 6.4$ & & \\
\hline Factor 2- postoperative & & 0.69 & 0.488 \\
\hline Right & $5.4 \pm 2.1$ & & \\
\hline Left & $5.1 \pm 2.2$ & & \\
\hline
\end{tabular}

QuickDASH: Quick Disabilities of the Arm, Shoulder and Hand; TOS: Thoracic outlet syndrome; SD: Standard deviation.

between right- and left-sided arterial TOS, only the mean postoperative Factor 1 scores were found to be significantly different $(\mathrm{t}=2.17, \mathrm{p}=0.032)$ (Table 5).

\section{DISCUSSION}

In the present study, the QuickDASH questionnaire was found to be a valid and reliable instrument to be used in the evaluation of patients with arterial TOS. The QucikDASH scale in TOS patients consisted of two factors, physical and functional. As a result of the comparison of the pre- and postoperative QuickDASH scores, the treatment applied to the patients provided a significant reduction in the total scores of the QuickDASH and physical and functional subscale scores. In addition, in the postoperative comparison between right- and left-sided arterial TOS, functional subscale scores were significantly higher in the right-sided arterial TOS patients.

Previous studies showed that DASH scores of patients with venous TOS did not change statistically significantly after surgery, while postoperative DASH scores of patients with neurogenic TOS statistically significantly differed. ${ }^{[7]}$ In a retrospective study, the long-term functional results of TOS surgical treatment were satisfactory and, in these cases, the QuickDASH scores decreased in the postoperative period, while the mean QuickDASH scores were higher than healthy individuals. ${ }^{[8]}$ In this study, we found that the QuickDASH was a valid and reliable measurement tool for measuring the symptoms of disease in patients with TOS, consistent with the literature. Moreover, the QuickDASH questionnaire consisted of two factors in TOS patients, one of which included the effects of the disease on functionality, quality of life and social life of the patient, and the other factor measured the severity of physical pain. As a result of these findings, we can speculate that arterial TOS, a disease that causes physical problems in the region of the arm, shoulder and hand, disrupts the functionality of individuals due to this physical effect.

About $90 \%$ of patients with TOS achieve a significant improvement as a result of the treatments applied, the decrease in the symptoms of the disease may vary according to the type of TOS and, in addition, nearly half of the patients can show full recovery after the surgical procedure. ${ }^{[6,7,10,11]}$ As a result of interviews with patients operated two years ago, it was found that functional status of patients with TOS were good in $49.4 \%$, fair in $34.6 \%$, and poor in $8 \%{ }^{[12]}$ In the present study, the mean scores of QuickDASH and subscale scores of the patients with TOS decreased significantly. In other words, the surgical procedure applied to patients was an effective method to treat TOS and the QuickDASH questionnaire was one of the measurement tools which could reflect this change. However, when the responses to the QuickDASH sub-items were 
examined, more than $53 \%$ of the patients had at least one mild difficulty after six months. Therefore, it may be useful not to ignore the ongoing symptoms after surgery in the region of the hand, arm and shoulder, and to refer these patients to the physical therapy and rehabilitation department, cardiovascular surgery, neurosurgery, and neurology departments. In addition, surgical procedure is a stressful condition and non-organic somatic or anxiety-related physical symptoms may develop after surgery. ${ }^{[13,14]}$ Therefore, it may be useful to examine the symptoms of nonorganic origin and consult patients to the mental health professionals for psychological support after surgery. Of note, treating physicians can inform their patients in detail about this issue.

It is well known that as individuals become older, arterial problems increase gradually ${ }^{[15]}$ In this study, we observed a positive correlation between the age and QuickDASH scores. Advanced age may be associated with increased symptoms of TOS, increased arterial problems in later ages, and prolonged recovery after surgery. In addition, functional problems were more frequently seen in right-sided TOS patients at six months. This result may be related to the fact that individuals use their right hands more often. Although pain symptoms were similar in the postoperative period, further research can be recommended to understand the greater functional symptoms in arterial TOS patients.

In the current study, on the other hand, the TOS symptoms were measured only with the self-report QuickDASH questionnaire, which can be deemed as a limitation of this study. The limited number of male patients is another limitation. Further large-scale, prospective, long-term studies are needed to draw a firm conclusion.

In conclusion, the QuickDASH questionnaire is a valid and reliable measurement tool consisting of two factors in the evaluation and follow-up of arterial thoracic outlet syndrome patients. The surgical procedure performed in these patients seems to be very effective at the end of six months. In addition, functional and physical symptoms associated with hands, arms, and shoulders may be seen in approximately half of the patients for the first six months. Therefore, it may be beneficial to treat these patients accordingly.

\section{Declaration of conflicting interests}

The authors declared no conflicts of interest with respect to the authorship and/or publication of this article.

\section{Funding}

The authors received no financial support for the research and/or authorship of this article.

\section{REFERENCES}

1. Jones MR, Prabhakar A, Viswanath O, Urits I, Green JB, Kendrick JB, et al. Thoracic outlet syndrome: A comprehensive review of pathophysiology, diagnosis, and treatment. Pain Ther 2019;8:5-18.

2. Gunal N, Dural K. Vascular thoracic outlet syndrome. Toraks Cerrahisi Bulteni 2014;5:102-5.

3. Sanders RJ, Hammond SL, Rao NM. Diagnosis of thoracic outlet syndrome. J Vasc Surg 2007;46:601-4.

4. Sanders RJ. Optimal approach to thoracic outlet syndrome: Transaxillary, supraclavicular, or infraclavicular. In: Ferguson MK, editors. Difficult Decisions in Thoracic Surgery. London: Springer; 2007. P. 495-502.

5. Chang DC, Rotellini-Coltvet LA, Mukherjee D, De Leon R, Freischlag JA. Surgical intervention for thoracic outlet syndrome improves patient's quality of life. J Vasc Surg 2009;49:630-5.

6. Peek J, Vos CG, Ünlü Ç, van de Pavoordt HDWM, van den Akker PJ, de Vries JPM. Outcome of surgical treatment for thoracic outlet syndrome: systematic review and metaanalysis. Ann Vasc Surg 2017;40:303-26.

7. Cordobes-Gual J, Lozano-Vilardell P, Torreguitart-Mirada N, Lara-Hernandez R, Riera-Vazquez R, Julia-Montoya J. Prospective study of the functional recovery after surgery for thoracic outlet syndrome. Eur J Vasc Endovasc Surg 2008;35:79-83.

8. Peek J, Vos CG, Ünlü Ç, Schreve MA, van de Mortel RHW, de Vries JPM. Long-term functional outcome of surgical treatment for thoracic outlet syndrome. Diagnostics (Basel) 2018;8:7.

9. Gummesson C, Ward MM, Atroshi I. The shortened disabilities of the arm, shoulder and hand questionnaire (QuickDASH): validity and reliability based on responses within the fulllength DASH. BMC Musculoskelet Disord 2006;7:44.

10. Peek J, Vos CG, Ünlü Ç, Schreve MA, van de Mortel RHW, de Vries JPM. Long-term functional outcome of surgical treatment for thoracic outlet syndrome. Diagnostics 2018;8:1-6.

11. George RS, Milton R, Chaudhuri N, Kefaloyannis E, Papagiannopoulos K. Totally endoscopic (VATS) first rib resection for thoracic outlet syndrome. Ann Thorac Surg 2017; 103:241-5.

12. Degeorges R, Reynaud C, Becquemin JP. Thoracic outlet syndrome surgery: long-term functional results. Ann Vasc Surg 2004; 18:558-65.

13. Carr EC, Nicky Thomas V, Wilson-Barnet J. Patient experiences of anxiety, depression and acute pain after surgery: a longitudinal perspective. Int J Nurs Stud 2005;42:521-30.

14. Tully PJ, Baker RA, Knight JL. Anxiety and depression as risk factors for mortality after coronary artery bypass surgery. J Psychosom Res 2008;64:285-90.

15. Bautista-Niño PK, Portilla-Fernandez E, Vaughan DE, Danser AH, Roks AJ. DNA damage: A main determinant of vascular aging. Int J Mol Sci 2016;17:748. 